\title{
Implementation of mental health services in conflict and post-conflict zones: Lessons from Syria
}

Mohammad Khalid Hamza and Madelyn Hsiao-Rei Hicks ${ }^{1}$

Clinical Mental Health, Lamar University-Texas State System, Worcester, USA, and former Board Member \& Chairman, SAMS Mental Health Committee, USA (2014-2020)

${ }^{1}$ Department of Psychiatry, University of Massachusetts Medical School, Worcester Recovery Center and Hospital, 309 Belmont St, Worcester, MA, 01604, USA

Address for correspondence: Dr. Mohammad Khalid Hamza, Clinical Mental Health, Lamar University-Texas State System, USA, and former Board Member \& Chairman, SAMS Mental Health Committee, USA (2014-2020). E-mail: hamzamk@lamar.edu

\section{Copyright : (c) 2021 Avicenna Journal of Medicine}

This is an open access journal, and articles are distributed under the terms of the Creative Commons AttributionNonCommercial-ShareAlike 4.0 License, which allows others to remix, tweak, and build upon the work non-commercially, as long as appropriate credit is given and the new creations are licensed under the identical terms.

\section{ABSTRACT}

\section{Objective:}

We describe the challenges confronted and lessons learned in implementing mental healthcare during the Syrian war to inform effective services for conflict-affected Syrian populations.

\section{Materials and Methods:}

We searched the academic and gray literature. We draw on the experiences of Syrian-American mental health professionals with nine years of experience providing clinical and programmatic mental healthcare in combat settings, siege, internally displaced person camps, and refugee camps.

\section{Results:}

Collaboration with nonprofessional personnel was essential due to the shortage of formally trained mental healthcare professionals in Syria. The use of psychological and diagnostic terms increased stigma, whereas asking about the patient's identified problem, "suffering," or "challenges" supported engagement. Warrelated trauma and horizontal violence commonly affect Syrian children, adolescents, and adults. Resilience and engagement were enhanced by sensitivity to patients' dignity, religious acceptance, and faith.

\section{Conclusions:}


The Syrian war remains an ongoing public health and humanitarian crisis in which mental healthcare must adapt rapidly to specific needs and resources of the patient and community. Psychiatrists can increase the acceptability and efficacy of their care by being sensitive to Syrian patients' experiences of horizontal violence, loss of dignity, stigma, worldviews in which religion and faith may be important sources of resilience, and culturally acceptable modes of communication.

Key words: Conflict, mental health, refugee, Syria, trauma, violence

\section{INTRODUCTION}

The Syrian war began in March 2011 and propelled rapidly into an ongoing public health crisis and humanitarian catastrophe. Violence and displacement have caused a high prevalence of trauma and serious mental health problems among Syrians both inside and outside the country, with mental healthcare needed in conflict zones, refugee camps, and among the internally displaced.[1,ㅡ, $\underline{3}]$ Due to the war, there are 5.9 million internally displaced persons (IDP) and 5.6 million refugees.[4] One-third of Syrian refugees are children aged 11 or younger, and two-thirds are women or minors aged 0-17 years.[్] Questions faced in delivering mental healthcare to conflict-affected populations include: What is the scope of mental healthcare? How is it constructed and delivered? Who delivers it and with what qualifications? What ethical and legal parameters exist? And finally, how to deliver mental health services without imposing a medical model on natural responses to extreme circumstances, especially in cultures with nascent mental healthcare and nonWestern views of disaster, illness, mental health, and spirituality? In this article, we aim at describing some challenges confronted in delivering mental healthcare services in the Syrian war in the hope that lessons learned can contribute to effective, acceptable services in conflict-affected populations.

\section{MATERIALS AND METHODS}

To establish context and background, the authors searched the academic and gray literature for publications by using the search terms "Syria," "humanitarian," "psychiatric," and "mental health." Publication references led to additional sources. We summarize and analyze observations and perspectives of the author MKH, a Syrian-American medical and forensic neuropsychologist, and a Syrian-American psychiatrist key informant who requested anonymity necessarily for reasons of protection, based on their nine years of experience during the Syrian war providing direct clinical and programmatic mental healthcare delivery and implementation in active combat areas, in siege conditions, in IDP camps, and in refugee camps in Syria, Lebanon, Jordan, Turkey, Greece, and Egypt as members of the Syrian American Medical Society (SAMS), a nongovernmental organization (NGO).[] Ethics approval was not required as the information in this article was not collected for purposes of a research study. It was not possible to obtain informed consent and it was not necessary as all cases were anonymized and cannot be deanonymized, and no individuals are identifiable.

\section{RESULTS}

\section{Responses must adapt quickly to changing, local needs}

After the initial shock when a small demonstration in the town of Daraa transmuted rapidly into a nationwide war, SAMS responded by transforming itself from a consortium for medical professionals of Syrian descent to a medical relief NGO to provide frontline and long-term crisis relief and healthcare to all affected by the Syrian war. Similar to other relief organizations, SAMS initially prioritized treating severe physical injuries over mental health needs. As millions of Syrians were displaced or living under sustained conflict, mental healthcare became essential. 
The minimal mental health system in Syria prior to the crisis, coupled with large-scale mental healthcare needs amplified by the war, made it impossible for SAMS and other NGOs to begin programs with adequate formally qualified staff due to preexisting shortfalls of mental health professionals. Shortfalls worsened after attacks targeted healthcare professionals, medical hospitals, and psychiatric facilities.[토, $\underline{6}, \underline{6}, \underline{7}]$ Consequently, provision of mental healthcare and psychosocial support (MHPSS) was adaptive, relying on expatriate healthcare professionals, ad hoc and formally trained nonprofessional personnel and refugees, and telepsychiatry for training, supervision, and consultations with Arabic-speaking psychiatrists and neurologists.[1,7] preexisting medical networks such as SAMS and the Syrian Expatriates Medical Association could adapt quickly and flexibly with efficient communication networks that facilitated rapid, effective mobilization of resources, for example, to provide MHPSS in besieged conflict areas.[]] The first and main challenge was the scope of mental healthcare needs, as shown here.

In 2012, Ghouta's population of 500,000 was besieged. For six years, government forces allowed no medicine or food to enter. Repeated bombardments caused numerous civilian casualties. Residents were left to their own resilience and resources to deal with the catastrophe. The SAMS MHPSS programs relied on a key individual; a charismatic local woman in her 20s with no formal training in mental healthcare. She led a team of 12 semiprofessionals to provide psychological support and social services, with a psychiatrist consulting by telepsychiatry. She maneuvered their way through a complex social system controlled by rebel groups to provide individual and group therapy to children, adolescents, and mothers who were particularly isolated or vulnerable to aggression or neglect. She did not go door-to-door generally offering "support." Instead, she sought out the most highly vulnerable: children wandering the streets, impaired individuals who might be exploited to smuggle bread through checkpoints, those with preexisting developmental and psychiatric problems, children and adolescents with temperament problems, and widows lacking social support. The scope of care was focused on those least capable of adapting to the catastrophe. The team focused on empowering them by teaching them adaptive communication and social skills. Children were provided with schooling and with meals to prevent sexual exploitation given that food was scarce.[1] Following the emergency evacuation of Ghouta in 2018, SAMS provided mobile clinics and treatment at temporary IDP camps.[]] MKH

The second challenge was how to deliver socio-culturally appropriate mental healthcare in a humanitarian emergency involving great loss of life and a collapse of social and moral order. Consensus has emerged that to increase the scale of services and logistical and cultural accessibility, mental healthcare in humanitarian emergencies benefits from integration into primary care and systematic inclusion and training of nonprofessionals and peer-refugees. $[\underline{1}, \underline{3}, \underline{6}, \underline{7}, \underline{9}, \underline{10}]$ Models for training primary care clinicians and nonprofessionals have been developed such as the WHO mhGAP and Problem Management Plus programs, both of which were adapted for use with Syrian refugees.[ㅌ, $\underline{3}, \underline{7}, \underline{10}, \underline{11}]$ However, Western centrally developed models of service delivery and research are sometimes rigidly structured and monolithic, with modifications for local populations limited to language or idioms of distress. What is "best practice" in one setting is not necessarily best practice, or feasible, in another. A bottom-up strategy for service and research development

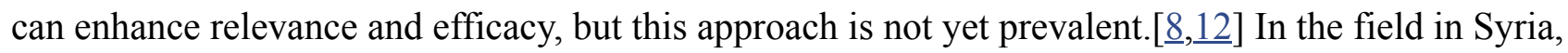
interventions often lacked context and relevance for the population who was not necessarily consulted on their needs or the basic premise of evaluation and treatment tools. In the gap between distant ideals and local needs those who were trained to conduct day-to-day evaluations and treatment often adjusted tools by omitting elements, "translating" them, or adding interpretations. Compared with models of structured, frequent supervision, in the field supervision was unstructured, infrequent, and unverifiable. To optimize relevance and efficacy, mental healthcare providers and models must not only adapt to specific sites, cultures and needs, but also arise from them. 
Syrian refugees typically have no prior exposure to mental healthcare and consider psychological problems stigmatizing. Indeed, Syrians often experience Western, psychologized terms and therapies as intellectual exercises foreign to their experience rather than real support. Instead of superimposing frameworks of meaning and communication, it is more helpful to ask and to respond to identified difficulties.[이, 11] In the case referred to later, refugees responded to beginning with an apology, light social interchange, and asking them to identify their main "challenge" - a term conveying personal agency and ability.

The first time I went to Lebanon to see what I could do to help, I found a program already operating. The staff were not sure of how to help those they reached out to. They had been told to go to tents and give people questionnaires. The questionnaires asked up to 90 seemingly arbitrary questions translated from English on symptoms and personality traits. One day, I took the team to visit a tent where we found two women. I apologized for our intrusion, introduced myself as an SAMS member-I never introduced myself as a "mental health worker" - and said we were there to ask how we could best help them. After light conversation, the two left and returned with other women. I asked them, "What is it like to not have a home? What is the biggest challenge?" All of them said that what was most difficult was dealing with the children. They said that the children want to play, and they cannot stay in a tent, but they are in a place they do not know, where police monitor them and target them for illegal status, so they have to stop the children from leaving the tent. I asked, "How can you control your children?" They said that beating was the only way. One mother described having different types of sticks for different types of offenses. She had to hide the sticks because the children started stealing them and throwing them away. In Syria, she lived in her own house. Now she lived in a tent. She worked because of her husband's illness, woak up at dawn, treated him with a traditional remedy, and cleaned the tent, only to find that her boys had wet their bedding. She would lose control and start beating them like a mad person. One day, she ran to the border checkpoint, grabbed a guard's rifle, pointed it at her head and begged him to shoot, screaming, "Are you not a man? I am an illegal Syrian, can't you see? No one will blame you! Just do it!" How could I counsel this woman? She said that she did not have a "psychological problem." Her initial response when offered support was, "You want to help me? Just take me back to my house." Only when I reminded of her of never hitting her children before, of how she had changed, and of the guilt she felt due to her violence toward them, only then there was a window to her pain and suffering. As she narrated her story, other women began to realize how they were treating their children. Many cried and narrated how their husbands, many of whom had been tortured, did the same to them. A Syrian-American psychiatrist

\section{Trauma propagates horizontal violence}

Horizontal violence is a substantial problem for Syrian refugees, as for other victims of collective trauma, and it needs to be sensitively explored. Domestic violence by mothers against children is elevated in Syrian refugee camps, with mothers' exposure to war trauma associated with poorer maternal mental health and greater use of harsh punishment, an effect decreased by having greater social support.[4, 13] Syrian parents keenly wish to parent their children as best possible under extraordinary conditions and benefit from locally developed community education on parenting and behavioral symptoms in children.[1, 14] As in other conflict-affected populations, domestic violence by men is elevated,. Evidence-based services to men include anger management and positive parenting.[9] Women and children are among the most vulnerable of refugees, experiencing domestic violence, gender-based violence, forced or child marriage, confinement, harassment, survival sex, and child labor. $[\underline{4}, \underline{9}, \underline{15}, \underline{16}]$ Sexual and gender-based violence increased substantially during the Syrian war and those known or thought to have experienced it can be highly stigmatized.[]] Men and women may avoid disclosing intimate, stigmatizing experiences to a male practitioner. Having choice of a male or female practitioner can ease sensitive disclosures.[으, 15] In Syrian IDP camps, $15.8 \%$ of males over age 14 had been detained or kidnapped and $11.3 \%$ tortured or beaten.[17] Torture survivors present with complex emotional, social, physical, and identity problems that are not well 
served by multiple diagnoses, but symptom reduction in one area can beneficially affect others.[9] Torture survivors can have difficulty trusting medical authorities. Mistrust in authority arising from political oppression is widely felt among conflict-affected Syrians and projected onto healthcare systems, especially mental healthcare, which attempts to uncover thoughts and feelings.

\section{Humility in professionals}

The assumption that people exposed to violence, atrocities, or displacement are targets for one's "support" or "therapy" can be offensive to conflict-affected Syrians. Using professional jargon such as "psychological," "mental health," and psychiatric labels (e.g., "depression") can exacerbate stigma and distrust. Universal terms such as "suffering" are more acceptable. Patients often express distress indirectly or through somatic complaints (e.g., "I'm so tired"), which may reflect the Islamic understanding of the body and soul as interdependent, interwoven entities and experiences. Cultural resources for non-Arabic-speaking mental healthcare professionals include close collaboration with Arabic-speaking colleagues to avoid cultural and linguistic missteps, and guidance on cultural frameworks, idioms of distress, explanatory models, and social and historical context of the Syrian conflict.[9] It is important to avoid being directive or assertive in the clinical encounter. Assertive manner, claiming expertise, and predicting outcomes - all common in Western medical cultures-may offend the spiritual and cultural worldview of Syrians because only God has ultimate knowledge.[9] One needs to listen closely to the views of patients who are already hyperaware of insults to their agency and dignity in the midst of conflict and displacement.

Case: The power of humility A 25-year-old woman of high social status lived in a suburb where male residents were systematically humiliated. Men were taken to nearby fields and forced to stand for days with no food or water. Many died. Many were forced to sign documents stating they were terrorists and giving up ownership of homes. She now lived in a tent, her husband psychologically paralyzed, with her mother-in-law directing her daily on cleaning the tent. She was referred to me by the medical clinic she visited daily for unremitting headaches asking, "What is wrong with my head?" I interpreted her psychological trauma, loss of status, the pain of lacking her husband's support, and being under the merciless critique of her mother-inlaw. She smiled sarcastically and said that I was doing the same as all doctors, "Every doctor thinks that their explanation is the one. Some tell me it is migraine. Another tells me it is my sinuses. Some say I need a CT scan, and now you are saying I am crazy." It was then that I realized what she was trying to say - that no one understands, that no one will ever find a solution, and all are empty promises of things getting better. I apologized to her for "daring" to simplify things in an insulting way. She took that well, and to my surprise accepted an antidepressant. A Syrian-American psychiatrist

\section{Mental illness in sustained conflict and trauma}

Exposure to trauma is high in Syrian refugees and occurs at all stages of the journey. Among refugees in Greece, 31-77.5\% experienced at least one violent event in Syria (mainly bombings), 24.8-57.5\% during the journey to Greece (mainly beatings), and 5-8\% in the Greek settlement (mainly beatings).[18] Among Syrian refugees in Turkey, $72.7 \%$ had experienced or witnessed the death of a close friend, family member, spouse or child; $48 \%$ had experienced or witnessed the abduction of a close friend or family member; $42 \%$ had experienced or witnessed a close friend's or family member's torture; and 50.6\% had touched or seen dead bodies.[19] Among IDP Syrians, 31.7\% overall, and 9.8\% of children younger than 15 years experienced at least one violent episode within the past year, in most cases witnessing atrocities (floggings, executions, and public body displays).[17]

Case: Trauma exposure in a Syrian child A young girl witnessed militants execute her father and then repeatedly rape her mother until she died. The next day, they took her to her school, ridiculed the teachers, and beat her and her classmates. When a male teacher came to her aid, they tied two ropes around his neck 
and pulled until he died. When a female teacher tried to help the children, they poured gasoline on her and burned her alive. This girl is now orphaned and lives in the unstable environment of a refugee camp.

Sixty percent of Syrian schoolchildren aged 8 through 15 have at least one probable psychological disorder, most commonly PTSD (35.1\%), followed by depression and anxiety.[20] One-third of Syrian adolescent refugees in Jordan have moderate-to-severe PTSD, with risk elevated for females and adolescents with one or both parents deceased.[21] Among adult Syrian refugees, approximately 30-40\% have PTSD, which is often comorbid with depression and anxiety.[19,22,23] Assessment of function is important because self-report and symptom scales used in conflict-affected populations can overestimate prevalence by 1.5 to 2 times, [ $\underline{3}]$ and because function is part of resilience.[12] Among IDP Syrians, 37.7\% of household members over two years old were so distressed that they were completely or almost completely inactive because of these feelings in the two weeks preceding the survey. $14.4 \%$ felt so hopeless that most of the time they did not want to carry on living. Among children aged 5-12 years, one-fifth had frequent bedwetting, a common sign of trauma and distress in this age group.[17]

As observed by SAMS mental health specialists, early in the conflict many Syrians experienced mental health symptoms consistent with established mental health disorders of anxiety, depression, and PTSD. The confluence of past and ongoing complex trauma over nine years of diminishing dignity, well-being, and hope while continuing to experience violence, displacement, and humiliation has pushed mental distress beyond traditional PTSD. $[\underline{1,11]}$ For individuals with severe mental illness, treatment and illness course can be profoundly affected by conflict.

A therapist's account from Idlib (Names have been changed) When Ahmed entered the clinic he examined everything obsessively with his eyes. He said, "I look in the mirror for hours and ask my mother, 'Do you see on my face or hands white spots?' I despair from checking my hands and my body.” I asked, "Can you remember the beginning of your suffering?" He said, "I stayed in Aleppo for six years alone in a building where only cats and an elderly neighbor remained. Days were miserable and dark. We only saw at night by the glow of missiles. My brother Ami...went missing in Aleppo. My beloved left me for Turkey...I was cut off from all my friends...I feel bad for my brother Tariq more than anything. He has not left the house for two years. He is schizophrenic, that's what they told me. God doesn't bless the officer who beat him and put him in prison... for 52 days. And he was tortured, beaten, berated, and he finally came out of the prison as a mentally ill patient, helpless... My hair is falling out. I have dropped my studies. I can't work. Most of my time is spent in my room." He wept. Ahmed saw me for five months and was excited about psychotherapy. It was a long time until he returned so I knew he was displaced again. He promised me a surprise on the next visit. He said, "I will bring you Tariq." For the first time in two years, Tariq will come out of the house. Told by telepsychiatry to $\mathrm{MKH}$.

\section{Mental health provider dilemmas}

Mental healthcare providers may struggle to maintain equilibrium while carrying vivid knowledge of the trauma, losses, and psychological wounds of their patients.[1] They themselves may have undergone trauma from war violence and displacement. Self-care can be difficult or infeasible under Syrian conflict conditions and burnout can occur.[1] Psychosocial support for healthcare providers in Syria is minimal.[24] Programs for well-being, training, and supervision are critical for healthcare workers to aid them while coping with danger, stress, and moral distress while working with conflict-affected Syrians.[ㄱ, 25]

Psychiatrists and other physicians in Syria risk arrest and torture by the Syrian government, which criminalized the provision of healthcare to whomever it considers opponents, in violation of the Geneva Conventions.[련 25] Opposition militias may endanger and interfere with healthcare provision. Mental health 
assessment and treatment is complicated by Syrian law, which deems attempted suicide a crime. Some refugee host countries require clinicians to report attempted suicides.[9]

\section{Religion, fate, and resilience}

Acceptance of fate when suffering is a characteristic of Islam that IA found had a fundamental role in the therapeutic alliance. For many Syrians, faith and reliance on God's strength supports hope, transforms healing, and enables moral transcendence over otherwise intolerable experiences. When dealing with trauma in conflict-affected Syrians, rather than focusing exclusively on signs and symptoms of illness and distress, accepting a patient's view of the supreme power of moral victory can support their resilience and healing.

Case: Acceptance and resilience I was introduced at the refugee camp to a woman who had lost five of her children. They had all volunteered for the Free Syrian Army and died within months. I asked how she was doing and she answered with an expression of peace on her face, "Praise to God." (In Arabic, the rest of the phrase is "God is the only one we praise for bad things.") I literally did not know what to say. The next day, in the government-controlled area of Syria I met an acquaintance who was now a medical officer in the Syrian Army. I asked how he was doing. He looked miserable and exhausted. He complained about his income and how "those opposition fighters" ruined the country. He declared, "We are victorious. We will take back the country." Inwardly, I compared the misery on the face of the officer who was "victorious" with peaceful look on the face of the woman who lost her children, who lived in a tent, and who had to work a whole day for one dollar, but praised God. I asked myself, "Is trauma an illness of the perpetrator or of the victim? Whom should I treat?” A Syrian-American psychiatrist.

Resilience in conflict-affected environments is affected by the phase of conflict, gender, age, intraindividual variables, and sociocultural context. Resilience promotion should be tailored to these specifics, with more focus on strengths and agency than on deficits and symptoms.[11, 12] Religious identification, which is diverse in Syria and does not necessarily indicate that an individual is devout, can be part of an individual's framework for spiritual, moral, cultural, socially affiliative and politically affiliative relationships with self, others and existential meaning. Prayer is a common, important way to reduce tension and stress among Syrians. Adolescents have reported that thinking of former good times and reading the Quran are helpful coping practices.[]]

\section{Mental healthcare capacity and stigma}

Mental health services in Syria were scarce and disorganized before the war with fewer than 50 psychiatrists, no other licensed mental health disciplines, and no mental health code. The war decimated Syria's mental healthcare capacity by triggering an outflow of healthcare professionals, $[\underline{1}, \underline{2}, \underline{6}, \underline{7}]$ by extensive damage and temporary closure of Syria's two public psychiatric hospitals after targeted bombardment, and by the complete destruction of Syria's two private psychiatric hospitals.[ㄹ] Mental healthcare before the war was limited in part by low public acceptance of mental healthcare and stigma. Shared wartime experiences of extreme stress and distress from violence, loss, and displacement have decreased stigma, increased recognition of the value of mental healthcare, and shifted explanatory models of mental illness. Recognition of the psychological impact on children and adolescents of war-associated loss and trauma has resulted in some school-based mental health programs to improve teachers' understanding of students' mental health needs and means of addressing them.[2]

\section{DISCUSSION}

\section{Limitations}


The observations and experiences described in this article might not represent those of other mental health specialists who have worked with conflict-affected Syrians. This article does not represent the views of SAMS. Similar MHPSS is provided by other NGOs. The implementation and impact of the mental health and resilience interventions described are limited by varying degrees of adversity, insecurity, and resources in the environment, and their effectiveness has not been thoroughly assessed in the Syrian conflict.

\section{CONCLUSIONS}

The Syrian war continues to cause an ongoing public health and humanitarian crisis, of which serious mental health problems and complex trauma are major components due to the scale of violence and atrocity coupled with severe stress from displacement, loss of security, and refugee conditions. Mental healthcare must be ready to adapt rapidly and effectually to the specific needs and conditions in which it is provided, which may include limited mental healthcare professionals and patient and community needs for basic safety and shelter. By being sensitive to patient experiences of horizontal violence, loss of dignity, stigma, worldviews in which religion and faith may be important sources of resilience, and culturally acceptable modes of communication, psychiatrists can provide greatly needed, effective care.

\section{KEY POINTS}

- Nine years of war in Syria have resulted in a severely traumatized population, which includes 5.9 million internally displaced Syrians and 5.6 million refugees, of whom two-thirds are women or minors.

- Prevalent trauma and mental health problems require large-scale implementation of mental healthcare that is culturally appropriate, feasible, and acceptable.

- Due to the shortage of formally trained mental healthcare professionals in Syria, mental health training and collaboration with nonprofessional personnel are essential.

- Many conflict-affected Syrians suffer from horizontal violence, torture, loss of home and loved ones, and the stress and stigma of living in refugee camps. Those with preexisting developmental and psychiatric problems are especially vulnerable.

- Use of psychological and diagnostic terms increases the cultural stigma of mental healthcare, whereas asking about the patient's identified problem, "suffering," or "challenges" supports engagement and decreases stigma.

- Resilience and clinical engagement are enhanced by sensitivity to Syrian patients' dignity and to personal and cultural resources of faith-based religious acceptance.

- Further research and inquiry into the needs and interventions identified by clinicians and personnel in the field can improve the relevance and efficacy of mental healthcare implementation in conflictaffected populations.

\section{Financial support and sponsorship}

Nil.

\section{Conflicts of interest}

There are no conflicts of interest. 
We gratefully thank the key informant who contributed their experiences and views to this paper, and all others who have dedicated their efforts to mental health for Syrians affected by war.

\section{REFERENCES}

1. Aburas R, Najeeb A, Baageel L, Mackey TK. The Syrian conflict: A case study of the challenges and acute need for medical humanitarian operations for women and children internally displaced persons. BMC Med. 2018;16:65. [PMCID: PMC5946430] [PubMed: 29747641]

2. Alpak G, Unal A, Bulbul F, Sagaltici E, Bez Y, Altindag A, et al. Post-traumatic stress disorder among syrian refugees in turkey: A cross-sectional study. Int J Psychiatry Clin Pract. 2015;19:45-50. [PubMed: $25195765]$

3. Barkil-Oteo A, Abdallah W, Mourra S, Jefee-Bahloul H. Trauma and resiliency: A tale of a Syrian refugee. Am J Psychiatry. 2018;175:8-12. [PubMed: 29301428]

4. Ben Farhat J, Blanchet K, Juul Bjertrup P, Veizis A, Perrin C, Coulborn RM, et al. Syrian refugees in Greece: Experience with violence, mental health status, and access to information during the journey and while in Greece. BMC Med. 2018;16:40. [PMCID: PMC5848526] [PubMed: 29530041]

5. Charlson F, van Ommeren M, Flaxman A, Cornett J, Whiteford H, Saxena S. New WHO prevalence estimates of mental disorders in conflict settings: A systematic review and meta-analysis. Lancet. 2019;394:240-8. [PMCID: PMC6657025] [PubMed: 31200992]

6. Cheung Chung M, AlQarni N, AlMazrouei M, Al Muhairi S, Shakra M, Mitchell B, et al. The impact of trauma exposure characteristics on post-traumatic stress disorder and psychiatric co-morbidity among Syrian refugees. Psychiatry Res. 2018;259:310-5. [PubMed: 29100134]

7. Duclos D, Ekzayez A, Ghaddar F, Checchi F, Blanchet K. Localisation and cross-border assistance to deliver humanitarian health services in North-West Syria: A qualitative inquiry for the lancet-AUB commission on syria. Confl Health. 2019;13:20. [PMCID: PMC6537164] [PubMed: 31149026]

8. El-Khani A, Cartwright K, Redmond A, Calam R. Daily bread: A novel vehicle for dissemination and evaluation of psychological first aid for families exposed to armed conflict in Syria. Glob Ment Health (Camb) 2016;3:e15. [PMCID: PMC5314739] [PubMed: 28596884]

9. Hassan G, Kirmayer LJ, Mekki-Berrada A, Quosh C, el Chammay R, Deville-Stoetzel JB, et al. Culture, Context and the Mental Health and Psychosocial Wellbeing of Syrians: A Review for Mental Health and Psychosocial Support Staff Working with Syrians Affected by Armed Conflict. Geneva: UNHCR; 2015. p. 52.

10. Hedar M. Mental health during the Syrian crisis: How Syrians are dealing with the psychological effects. Int Rev Red Cross. 2017;99:927-35.

11. Hughes P, Hijazi Z, Saeed K. Improving access to mental healthcare for displaced Syrians: Case studies from Syria, Iraq and Turkey. BJPsych Int. 2016;13:84-6. [PMCID: PMC5619488] [PubMed: 29093914]

12. Johns Hopkins Bloomberg School of Public Health, International Rescue Committee, Syrian American Medical Society. Reality Makes Our Decisions: Ethical Challenges in Humanitarian Health in Situations of Extreme Violence: Report and Recommendations. Baltimore, MD: Johns Hopkins; 2019. p. 36.

13. Perkins JD, Ajeeb M, Fadel L, Saleh G. Mental health in Syrian children with a focus on post-traumatic stress: A cross-sectional study from Syrian schools. Soc Psychiatry Psychiatr Epidemiol. 2018;53:1231-9. [PMCID: PMC6208941] [PubMed: 30083987] 
14. Rubenstein L, Fallon K, Sahloul Z, Rihawi H, Szybala V, Philhower C, et al. Washington, DC: Syrian American Medical Society; 2015. Syrian medical voices from the ground: The ordeal of Syria's healthcare professionals; p. 27.

15. Reese Masterson A, Usta J, Gupta J, Ettinger AS. Assessment of reproductive health and violence against women among displaced syrians in lebanon. BMC Womens Health. 2014;14:25. [PMCID: PMC3929551] [PubMed: 24552142]

16. Sim A, Bowes L, Gardner F. The promotive effects of social support for parental resilience in a refugee context: A cross-sectional study with Syrian mothers in lebanon. Prev Sci. 2019;20:674-83. [PMCID: PMC6541567] [PubMed: 30684214]

17. Sijbrandij M, Acarturk C, Bird M, Bryant RA, Burchert S, Carswell K, et al. Strengthening mental health care systems for Syrian refugees in Europe and the Middle East: Integrating scalable psychological interventions in nine countries. Eur J Psychotraumatol. 2017;8(Supp 2):1388102. 10.1080/20008198.2017.1388102. [PMCID: PMC5687806] [PubMed: 29163867]

18. Syrian American Medical Society. Human Devastation Syndrome: The Impact of Conflict on Mental Health. Washington, DC: SAMS Mental Health Committee, Syrian American Medical Society; 2018. p. 37. Available from: https://www.sams-usa.net/reports/human-devastation-syndrome-the-impact-of-conflict-onmental-health/

19. Syrian American Medical Society. SAMS Annual Report 2018. Vol. 88. Washington, DC: Syrian American Medical Society; 2019. Available from: https://www.sams-usa.net/reports/sams-annual-report$\underline{2018 /}$

20. Tinghög P, Malm A, Arwidson C, Sigvardsdotter E, Lundin A, Saboonchi F. Prevalence of mental ill health, traumas and postmigration stress among refugees from Syria resettled in Sweden after 2011: A population-based survey. BMJ Open. 2017;7:e018899. [PMCID: PMC5778338] [PubMed: 29289940]

21. Tol WA, Song S, Jordans MJ. Annual research review: Resilience and mental health in children and adolescents living in areas of armed conflict-a systematic review of findings in low- and middle-income countries. J Child Psychol Psychiatry. 2013;54:445-60. [PubMed: 23414226]

22. UNHCR. Operational Portal Refugee Situations: Situation Syria Regional Refugee Response. Percentages were calculated from: Registered Syrian Refugees - Demography [Internet] Geneva: UNHCR; 2019. Available from: https://data2.unhcr.org/en/situations/syria .

23. UNOCHA. United Nations Office for the Coordination of Humanitarian Affairs. Humanitarian Response Plan Monitoring Report: January-May 2019. [19 October 2019]. p. 60. Available from: https://www.humanitarianresponse.info/en/operations/whole-of-syria .

24. Vernier L, Cramond V, Hoetjes M, Lenglet A, Hoare T, Malaeb R, et al. High levels of mortality, exposure to violence and psychological distress experienced by the internally displaced population of Ein Issa camp prior to and during their displacement in Northeast Syria, November 2017. Confl Health. 2019;13:33. doi: 10.1186/s13031-019-0216-y. [PMCID: PMC6624987] [PubMed: 31338121]

25. Yonis OB, Khader Y, Jarboua A, Al-Bsoul MM, Al-Akour N, Alfaqih MA, et al. Post-traumatic stress disorder among Syrian adolescent refugees in Jordan. J Public Health. 2019:fdz026. $10.1093 / \mathrm{pubmed} / \mathrm{fdz} 026$. 
